\title{
LOS OBISPOS DE CARTAGENA DE INDIAS DURANTE EL SIGLO XVIII: CRIOLLOS Y REGALISMO
}

\author{
POR \\ MANUEl SERRANo GARcía ${ }^{1}$ \\ Universidad de Sevilla
}

\begin{abstract}
RESUMEN
El obispado de Cartagena de Indias presenta las características propias de la Iglesia americana durante el siglo XVIII, a saber, criollismo e importancia del clero secular. No obstante, las particularidades de la ciudad de Cartagena permiten establecer nuevos puntos de vista sobre estos aspectos. La importancia del sector comercial en el patriciado urbano, condiciona el auge del criollismo en la ciudad que favoreció el número de obispos criollos. Al mismo tiempo, a pesar de la escasez de rentas y de ser un obispado de segundo orden, el periodo de vacantes se vio reducido respecto a otras zonas del virreinato, conllevando una mejora en la administración diocesana.
\end{abstract}

PALABRAS CLAVE: Historia de la Iglesia en América; Colombia; Cartagena de Indias; criollos; regalismo; siglo XVIII.

\section{THE BISHOPS OF CARTAGENA DE INDIAS DURING THE 18TH CENTURY: CREOLES AND REGALISM}

\begin{abstract}
The Bishopric of Cartagena de Indias shares the same characteristics as the American Church during the 18th century: the increase in number and importance of the creole people and the secular clergy. However, the especial features of the city of Cartagena gave rise to new points of view on these aspects. The growth of the commercial sector among the urban elite made the creole people as well as the creole bishops have a more relevant role in society. At the same, despite being an episcopate of less importance than others and having insufficient rents, the vacant period became shorter in relation to other areas of the viceroyship and all this also contributed to a great improvement in the diocesan administration.
\end{abstract}

KEY WORDS: American Church History; Colombia; Cartagena de Indias; Creoles; Regalism; 18th Century.

Cómo CITAR ESTE ARTículo / CITATION: Serrano García, M. 2018. «El obispado de Cartagena de Indias durante el siglo XVIII: criollos y regalismo». Hispania Sacra 70, 141: 211-222. https://doi.org/10.3989/hs.2018.017

Recibido/Received 07-02-2016

Aceptado/Accepted 10-02-2016

\section{INTRODUCCIÓN}

El estudio de las iglesias locales permite ampliar el conocimiento que disponemos sobre los cambios que se produjeron a lo largo del siglo XVIII en la Iglesia americana. Imprescindible resulta pues el estudio de los máximos dirigentes de estas iglesias: arzobispos y obispos, que en algunos casos llegaron a los máximos órganos de gobierno de la colonia.

1 manuelserrano13@gmail.com / ORCID iD: http://orcid.org/00000002-3221-1756
La jerarquía eclesiástica ha sido estudiada en su conjunto por P. Castañeda Delgado y J. Marchena Fernández², pero se echa en falta un estudio pormenorizado de un obispado concreto. ${ }^{3}$ El caso de Cartagena se presta a estos propósitos por ser una de las ciudades más importantes del siglo XVIII

2 Se trata de un estudio pormenorizado de distintas variantes en el conjunto del episcopado durante todo el periodo colonial. Castañeda Delgado y Marchena Fernández 1992.

3 Serrano García 2015. La tesis doctoral se centra en el estudio del obispado de Cartagena de Indias en su conjunto durante el siglo XVIII analizando todos los aspectos de la diócesis. 
americano y donde las autoridades peninsulares tuvieron que prestar gran atención frente al crecimiento de las élites locales y de las agresiones extranjeras. En consecuencia, la elección de los dos representantes regios más destacados, gobernadores y obispos, no debió ser una cuestión de poca importancia, sino que fue muy cuidada desde la Corona. ${ }^{4}$ Sin embargo, hasta la fecha la bibliografía sobre los obispos cartageneros ha sido escasa o centrada solo en la narración cronológica de los principales hechos de su gobierno, sin entrar a analizar su figura como actores principales del gobierno de la ciudad. ${ }^{5}$

El siglo XVIII se inició en Cartagena con una larga sede vacante y unos convulsos años de disputas. El último obispo del siglo XVII, Antonio María Benavides, había abandonado la ciudad para dirigirse directamente a Roma a solucionar unos problemas de competencias con las autoridades civiles, obispados vecinos e Inquisición, que habían dejado la ciudad y sus instituciones en entredicho. La Corona debía actuar con autoridad, devolviendo la calma a una ciudad clave para el comercio y el sostenimiento de Imperio en el Caribe. ${ }^{6}$ El carácter combativo del obispo había supuesto un verdadero quebradero de cabeza para las autoridades coloniales y especialmente para las peninsulares que solo pudieron descansar cuando se certificó que el obispo había fallecido, una vez de vuelta en el puerto de Barcelona. ${ }^{7}$ De ahí, que en adelante la elección del obispo de Cartagena fuera muy cuidada, pues se necesitaba pacificar la convulsa diócesis.

El elegido para ocupar la sede cartagenera era el propio inquisidor de la ciudad Juan de Layseca y Alvarado, aunque pronto le llegó la muerte al fallecer el 19 de diciembre de 1712. Debió ser fuerte el sentimiento de desasosiego por ver cómo la vacante se alargaba. De ahí que con la inminente llegada de un obispo a la ciudad para dirigirse a Popayán no se quiso perder la oportunidad y se le encargó el gobierno de la ciudad y diócesis. Se trataba de fray Antonio María Casiani, que llegó el 29 de agosto y un día después se presentó en el cabildo para tomar posesión de su cargo, con la lógica expectación de unos capitulares que llevaban varios años sin pastor. ${ }^{8}$ Hasta doce fueron los obispos que tomaron posesión de la sede cartagenera durante el siglo XVIII, quedando atrás cinco designados, pero que no llegaron a ocupar su puesto por diversas causas.

La evolución del obispado a lo largo de los años no muestra unos cambios significativos en los que se puedan distinguir varias etapas. Sin embargo, si lo observamos en conjunto al analizar distintas variantes, podemos entrever que a partir del siglo XVIII se agudizan unas tendencias, ya existentes en la centuria anterior, que permiten establecer una diferenciación propia para este siglo. Son estas tendencias las que nos permiten comprobar los cambios políticos y sociales que vivió la colonia a partir del siglo XVIII.

4 Por su parte, el caso de los gobernadores ha sido tratado en diversos estudios Borrego Plá 1983; Castillo Mathieu 1998.

5 Restrepo Posada 1955: 301-320.

6 Segovia Salas y Sourdis Nájera 2005: 270-317.

AGI, Santa Fe, 1168. El confesor real informa sobre la muerte de obispo de Cartagena. Madrid 19 de marzo de 1713.

8 Pacheco 1986: t. 3, I, 67.

\section{CARACTERÍSTICAS DEL EPISCOPADO}

La primera variante que podemos estudiar es el origen geográfico de los prelados, frente a siglos anteriores y siguiendo la tendencia de las provisiones de puestos eclesiásticos para América, la mitad de los obispos fueron de origen americano. Se designaron ocho americanos y ocho peninsulares, pero al no tomar posesión de la sede dos de origen americano, se decanta levemente la balanza por los peninsulares. Sin embargo, si observamos lo ocurrido en los siglos anteriores, los datos son mucho más significativos. Como era de esperar durante el siglo XVI todos los obispos fueron de origen peninsular, continuando la misma tendencia en el siglo XVII, ya que sólo uno de ellos fue de origen americano, el limeño Diego Ramírez de Cepeda, quien murió sin llegar a tomar posesión de la sede. Estos datos se corresponden, a rasgos generales, con los que se extraen del resto de diócesis americanas, el número de obispos criollos fue en aumento especialmente a partir de la segunda mitad del XVIII, salvo en las capitales virreinales donde el peso de los peninsulares fue más importante. Sin embargo, si para el resto de obispados americanos el cambio de tendencia comenzó a mediados del siglo XVII, para Cartagena hubo que esperar hasta el siglo XVIII. Incluso hubo que esperar hasta 1729 con el nombramiento de Manuel Antonio Gómez de Silva, quien fue removido antes de tomar posesión de la sede y no fue hasta la segunda mitad de siglo cuando se vio llegar a cinco obispos americanos. Esta evolución hay que relacionarla con el aumento de los centros de enseñanza americanos, pues facilitaba la formación de los nacidos en América que encontrarían más posibilidades de acudir a centros de formación. Especialmente fructíferos fueron los colegios de Lima que produjeron tres de los obispos cartageneros, mientras dos fueron de la propia ciudad, y otros dos de Quito y Michoacán.

GRÁFICO 1

Origen geográfico de los obispos

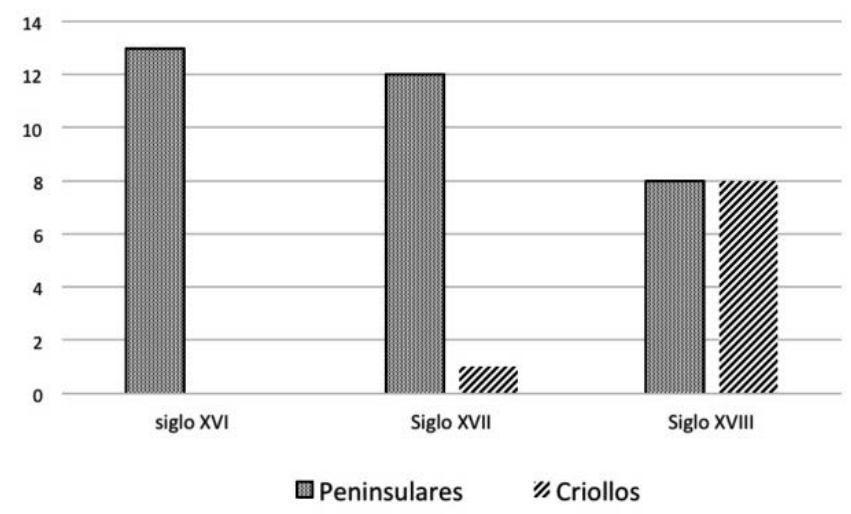

Fuente: AGI, Santafé, diversos legajos.

En este sentido de ascenso del clero criollo, es muy significativo el hecho de que por primera vez llegaran al obispado dos cartageneros: primero Bartolomé Narváez y Berrio, que gobernó la diócesis entre 1751 y 1754, y posteriormente, Jerónimo de Liñán y Borda, que lo hizo desde 1796 a 1805. Ambos iniciaron su carrera eclesiástica 
como prebendados de la catedral y fueron ascendiendo puestos dentro del cabildo eclesiástico hasta conseguir el reconocimiento episcopal. Bartolomé Narváez y Berrio por ambos progenitores pertenecía a una de las familias más notables de la ciudad. Tanto por línea paterna, los Narváez, como materna, los Berrio, que eran familias principales de la cuidad y habían ocupado y ocupaban, importantes cargos en el gobierno civil de la ciudad. La llegada de dos hijos de Cartagena a la silla episcopal iba a suponer un cambio importante para las generaciones criollas, pues se convertían estos obispos en una de las pocas autoridades nativas que regían la ciudad. Con anterioridad lo habían hecho varios gobernadores ${ }^{9}$, y como parecía lógico, era hora también de que le tocara a la Iglesia. Aunque autoridades delegadas del rey, la llegada a estos puestos no deja de ser la confirmación del triunfo de la clase criolla cartagenera.

Otra variante se refiere a la procedencia, que podía ser bien de órdenes religiosas, bien del clero secular. Si en el siglo XVI todos los nombrados eran pertenecientes a órdenes religiosas, en el XVII se igualaron los de una y otra procedencia, mientras que en el siglo XVIII solo hay dos religiosos, fray Antonio María Casiani de la orden de los Basilios, y el franciscano fray José Fernández Díaz de la Madrid. En esta tendencia se puede apreciar la cada vez menor influencia de las órdenes religiosas en la ocupación de puestos episcopales en Indias, igual que de forma paralela, dejaron paso a la entrada de seculares en otros puestos eclesiásticos, como las doctrinas o los curatos de las parroquias. Esta fue una tendencia general que siguieron las diócesis en los primeros siglos cuando tuvo mayor importancia la Iglesia misional; los obispados fueron ocupados por regulares, más preparados para llevar a cabo la labor evangelizadora. A medida que se fue fortaleciendo la Iglesia diocesana el peso del clero secular se hizo más importante para ocupar el lugar que las instituciones canónicas les tenían reservadas, mientras que los prelados regulares quedaron en su mayoría relevados a aquellos obispados donde la vocación misional aún era necesaria. Aun así, las órdenes religiosas no fueron relegadas del todo del episcopologio cartagenero, pues a los dos únicos obispos regulares del siglo XVIII, podría habérseles sumado algún otro nombramiento más. Ni las órdenes religiosas dejaron de solicitar estos puestos, como lo demuestra la solicitud por parte de los Trinitarios a la Cámara en 1775 tras el traslado de Agustín Alvarado, alegando que nunca habían tenido un obispo de su orden y recomendando tres candidatos. ${ }^{10}$ Por su parte, la Corona siguió también nombrando obispos religiosos para Cartagena, pues en 1725 se elegía como sucesor de Gómez Calleja al prior de los dominicos de Cádiz, Tomás del Valle, que al renunciar transfirió el nombramiento a Manuel A. Gómez de Silva. También en las mismas votaciones en las que salió elegido el franciscano José Fernández Díaz de la Madrid, iban en la lista un fraile carmelita y el comendador de la Merced de Cartagena, José Antonio de Montaño. ${ }^{11}$

9 Un estudio completo de todos los gobernadores de Cartagena lo encontramos en Castillo Mathieu 1998.

10 AGI, Santa Fe, 1049. Solicitud a la Cámara de los Trinitarios, 30 de octubre de 1775.

11 AGI, Santa Fe, 1168.
Este salto cualitativo de los clérigos seculares lo podemos ver reflejado en el gráfico 2, donde claramente se ve el cambio de tendencia, encontrándose el punto de inflexión en el siglo XVII. El cambio fue tan evidente que los obispos de origen regular casi llegaron a desaparecer durante el siglo XVIII. Esta variable está íntimamente relacionada con la anterior del origen geográfico. Los propuestos provenían principalmente y de manera exclusiva en el caso de los criollos de puestos relacionados con los cabildos eclesiásticos, lugar de representación de las nuevas élites criollas, que hicieron valer su peso social promoviendo a sus hijos a las más altas esferas eclesiásticas. ${ }^{12}$

En consecuencia, es inevitable establecer una estrecha relación con la variante criollo-secular, pues a pesar de que existieron obispos seculares de origen peninsular, la tendencia fue la contraria. En el caso de Cartagena esta tendencia estuvo marcada por otra circunstancia, la de que sólo uno de los candidatos criollos, Diego Peredo, proveniente de Nueva España, procedía de una región distinta al área andina. El resto de obispos provenían del Perú, de Bogotá y de la propia Cartagena, lo cual nos hace pensar en una fuerte regionalización de la Iglesia cartagenera, nutrida de los dos principales focos políticoreligiosos de la región.

GRÁFICO 2

Origen eclesial de los obispos

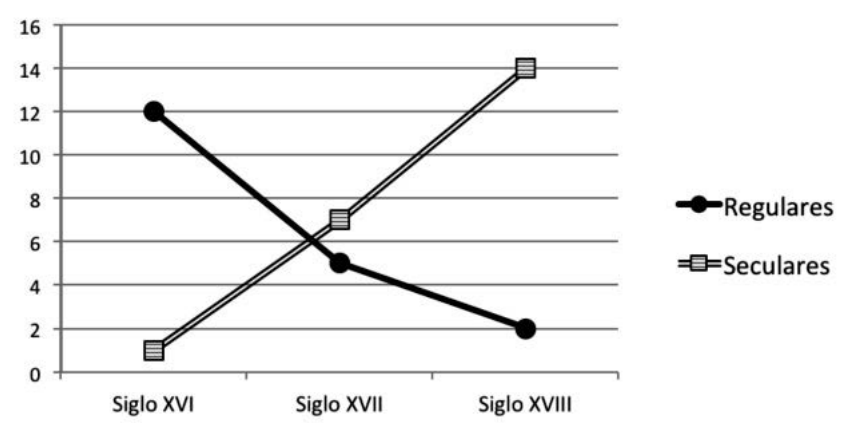

Fuente: AGI, Santafé, diversos legajos.

Otra variable que hay que destacar es la formación de los obispos y la serie de puestos que anteriormente habían ocupado. La mayoría de ellos eran doctores en teología y cánones, grado que habían conseguido tanto en universidades españolas como en las americanas, en los casos de obispos criollos. Entre los obispos de alta formación destacan el doctor en teología y catedrático de Alcalá, Antonio María Casiani o el obispo fray José Díaz de la Madrid, catedrático en filosofía y teología en Lima. No obstante, el grupo de obispos que habían seguido los estudios en derecho canónico y civil fue el más importante, más aún si lo comparamos con los siglos anteriores. Si durante los siglos XVI y XVII la formación predominante

12 Las propias autoridades coloniales promocionaron la entrada de los nacidos en América en los cabildos catedralicios y que quedó reflejada en las relaciones de mando de los virreyes neogranadinos. Informe emitido por el mariscal de campo Antonio Manso, como presidente de la Audiencia del Nuevo Reino de Granada, año 1729. En Colmenares 1989: 35 . 
fue la teológica, como no podía ser de otra forma, los obispos del siglo XVIII muestran una mayor diversidad en la formación. Una explicación a este fenómeno la podemos hallar en el aumento de clérigos de origen secular, pues entre ellos la formación en cánones era más común que entre los pertenecientes a órdenes religiosas. Sin embargo, no podemos pasar por alto el hecho de que muchos de los obispos, cuatro de ellos, fueran doctores o licenciados en derecho civil. Entre ellos destacan las figuras de Bernardo de Arbiza, que había ejercido de oidor en Panamá o de Diego Peredo, quien había obtenido una vez terminados sus estudios en cánones la autorización de la Audiencia de México para ejercer de abogado y posteriormente de juez eclesiástico del partido del que fue cura propietario. ${ }^{13}$

Podemos destacar este dato como característico de la diócesis de Cartagena, pues la tendencia general fue la disminución de los candidatos doctores en derecho civil, frente aquellos que lo eran en canónico. Las necesidades de las iglesias diocesanas hizo inevitable la elección de obispos formados en derecho canónico, para dirimir los problemas que se planteaban entre la Iglesia secular y regular, así como en los concilios provinciales. ${ }^{14}$ Los problemas concretos que había vivido la sede de Cartagena, especialmente a comienzos de siglo y la lejanía de la Audiencia de Santafé, pareció decantar las decisiones regias hacia los licenciados en derecho civil. Decisión que hay que poner en relación con la insistencia por parte de las autoridades civiles en que se buscara un provisor canonista, y que tantos problemas dio con las elecciones de sujetos que no cumplían con esos requisitos. Aun así, siguieron siendo importantes los obispos teólogos, siguiendo la tradición de siglos anteriores, en lo que también podemos intuir la presión de las élites criollas de la ciudad, pues los dos obispos cartageneros fueron ambos doctores en teología, al igual que el obispo de Santa Marta, Anselmo de Fraga, salido también del cabildo cartagenero.

Respecto a las funciones que habían desempeñado con anterioridad, todos ellos provenían de puestos eclesiásticos relacionados con cabildos catedralicios o de colegiatas, tanto peninsulares como americanas, por lo que carecían de experiencia pastoral en anteriores diócesis. Solo uno de ellos era obispo con antelación, el limeño Gregorio Molleda, quien a pesar de disfrutar de una media ración en la catedral de Lima -tenía el título de prelado doméstico del papa al ser nombrado obispo de la antigua Isauria - carecía asimismo de experiencia pastoral. ${ }^{15}$ El resto de obispos habían ocupado otros cargos. Los pertenecientes al clero regular habían desempeñado diversos puestos en sus respectivas órdenes, como Casiani que combinaba su labor docente con el cargo de definidor de su orden en Castilla y abad del colegio de Alcalá, lo mismo que José Díaz de la Madrid, que fue provincial franciscano de Quito, o Agustín de Alvarado, abad de la colegiata de Olivares en Sevilla y Miguel Álvarez Cortés, que lo fue del Sacromonte de Granada. El resto de

13 AGI, Indiferente, 220, n. 71. Méritos de Diego Peredo, Madrid 16 de octubre de 1729.

14 Catañeda Delgado y Marchena Fernández 1992: 115-116.

15 El cargo de prelado doméstico era una prelatura honorífica que concedía el papa a personas que formarían parte de la casa pontificia. Isauria era una antigua sede episcopal situada en Asia Menor. El episcopado de antiguas sedes extintas se concede a los obispos auxiliares. obispos de origen secular habían desempañado distintos cargos dentro de los cabildos eclesiásticos de distintas catedrales, así como lo habían hecho los dos cartageneros. Gómez Calleja había sido canónigo doctoral en Zamora, Diego Martínez Garrido vicario también en Zamora; Manuel de Sosa, arcediano en Caracas; Diego Peredo, deán en Michoacán y Blas Sobrino, vicario en Zamora. Tan sólo un obispo no había desempeñado ningún cargo eclesiástico de importancia: Bernardo de Arbiza que fue oidor civil en Panamá, y aun siendo solo diácono recibió del rey la presentación para el obispado de Cartagena. ${ }^{16}$

Por tanto, podemos calificar la sede Cartagenera como un obispado de primer destino, frente a otras sedes que recibían obispos con una experiencia anterior en otros obispados. La sede cartagenera se presentaba pues como un destino transitorio para alcanzar un obispado de mayor categoría, ya que se estimada en la corte solo como obispado secundario. Esta circunstancia provocó un continuo vaivén de obispos por la ciudad, con unos periodos de gobierno relativamente cortos. No obstante, la falta de experiencia pastoral y la provisionalidad en el cargo, no pueden ser vistas como un problema a priori para el gobierno de la diócesis. Los obispos cartageneros no encontraron dificultades para el desempeño de sus labores pastorales y los problemas que surgieron no tuvieron relación con esta falta de experiencia sino más bien con la toma de decisiones que limaban las prerrogativas de otros agentes sociales, tanto eclesiásticos como civiles, o bien otras que iban encaminadas a defender la jurisdicción episcopal. Por otro lado, tampoco se puede poner en duda su compromiso pastoral con su diócesis, la preocupación por las doctrinas, por el buen funcionamiento de las parroquias, por el buen tratamiento de indios y esclavos, todo ello ejercido a través de las numerosas y pormenorizadas visitas, que junto con la defensa de la autoridad episcopal y la autonomía de la jurisdicción, nos hace pensar en el fuerte compromiso de los prelados con su iglesia. Lo que podemos desprender de estos datos es que Cartagena fue preferentemente una sede de paso, en la que los prelados se vieron condicionados por diferentes motivos, pues la mayoría de ellos renunciaron a su sede o intentaron hacerlo.

\section{EL NOMBRAMIENTO DE LOS OBISPOS}

Los cambios que podemos observar en los sujetos en los que recaían las sedes episcopales, no se correspondieron necesariamente con un cambio significativo en proceso de elección diseñado por la Corona. El proceso de elección de los obispos poco varió a lo largo del periodo colonial, siguiendo los pasos marcados dentro del Patronato regio, pues ni

16 Los distintos cargos que ocuparon los obispos han sido recogidos de manera muy prolija por diversos autores, las primeras referencias bibliográficas son del siglo XVIII (Alcedo 1786: I, 393-399). P. Pacheco (1986), recoge de cada obispo una pequeña biografía, utilizando como fuente bibliográfica la obra de Ritzler y Sefrin 1952: V, 145-146; 1958: VI, 150-156. Por último, Martínez Reyes (1986) acompaña los documentos de cada prelado con una pequeña biografía en la que no aporta datos diferentes a los recogidos por el P. Pacheco. El Archivo General de Indias, Audiencia de Santafé, custodia en la sección Indiferente General diversos currículos, en concreto de los obispos Antonio María Casiani, Manuel de Sosa Betancourt, Diego Peredo y del electo Manuel Gómez de Silva. 
siquiera los nuevos aires regalistas de los borbones pudieron introducir novedades debido al fuerte control regio que se hacía de los nombramientos desde el principio de la colonia.

Algunos autores han relacionado el aumento del clero criollo y secular, que dio un salto cualitativo en el siglo XVIII, como una media propia del gobierno de los borbones. Así pues han destacado en este sentido el poco aprecio de las élites ilustradas a los miembros de las órdenes religiosas, prefiriendo por tanto miembros del clero secular. ${ }^{17} \mathrm{Sin}$ embargo, otros autores han relacionado esta medida directamente con el reformismo de los borbones, así pues para $A$. de Egaña la elección de clérigos seculares en contraposición a los regulares, la relaciona con un fortalecimiento del Patronato regio. ${ }^{18}$ En este mismo sentido, aunque sin citar expresamente el nombramiento de clérigos seculares se expresa A. de la Hera, al explicar la incorporación del clero al proyecto regalista. Carlos III tuvo que llevar a cabo una política eclesiástica a fin de hacer receptivo el clero americano a sus medidas regalistas, para lo que lógicamente era necesario controlar muy bien la elección de obispos con la intención de que fueran adeptos a las tesis regalistas. Por otro lado, la celebración de sínodos y el control de los seminarios era una pieza fundamental en la formación de un clero regalista. ${ }^{19}$ Podemos entender que para este proceder estaba más capacitado el clero secular frente al regular, más autónomo y más difícil de controlar en las enseñanzas impartidas en sus instituciones formativas, frente al control que pudo existir en los estudios de los propios seminarios diocesanos. ${ }^{20}$

En unos términos más concretos, no existió ningún criterio claro para elegir algún tipo de candidato, sino que dependió de las circunstancias de cada momento. Eso sí, las recomendaciones sobre el tipo de sujetos más adecuados para el gobierno de cada obispado fueron frecuentes, especialmente en Cartagena para los primeros años del siglo XVIII, debido a los convulsos años del gobierno de Miguel Antonio Benavides. Un ejemplo de estas recomendaciones se halla en las que hizo el confesor del rey a propósito del obispo Antonio María Casiani, cuyo turbulento gobierno comenzaba a recordar demasiado al de su antecesor:

Habiendo leído las dos consultas que V.M. se ha servido de remitirme, debo decir que de los desafueros de este docto sí, pero disparatado obispo de Cartagena, se puede sacar una buena observancia en adelante y es considerar que no siempre los ingenios que más brillan en las universidades son los más apropiados para el gobierno de las iglesias, y que no pocas veces será mejor para este un buen juicio sin letras que muchas letras sin juicio. ${ }^{21}$

Significativa cuando menos es la recomendación del confesor real frente a un obispo celoso de la defensa de sus intereses, ya que la Corona no estaba dispuesta a dejar los obispados americanos en manos de personalidades que pudieran acarrear continuos conflictos, sembrando

17 Catañeda Delgado y Marchena Fernández 1992: 80.

18 Egaña 1966: 1046.

19 Hera 1992: 461 y ss.

20 Hay que destacar que se trató de una media que afectó sobre todo a las sedes americanas, pues la elección de regulares para las sedes peninsulares continúo siendo elevada. Cortés Peña 2000: 160.

21 Pacheco 1986: 77. discordias como lo estaba haciendo el obispo Casiani. A pesar de que los acontecimientos del obispo Miguel Antonio Benavides quedaban ya lejanos, debieron estar presentes para elegir a candidatos que en principio no fueran propensos a levantar conflictos. De ahí que se consideraran muy importantes los informes que los obispos debían remitir a la corte con los posibles candidatos a los diversos puestos eclesiásticos. Respecto a los candidatos para sillas episcopales, estas informaciones eran relativas a los deanes de las distintas catedrales, donde se exponían las cualidades de los candidatos con unas anotaciones de los obispos, que se tendrían que tener muy en cuenta. Si observamos la recomendación del confesor trascrita anteriormente se vislumbra que el interés de la Corona por los posibles candidatos no iba dirigido hacia currículos destacados, sin obviar no obstante una adecuada formación, sino a informaciones del proceder de los clérigos en sus puestos, para lo cual las informaciones de autoridades civiles e inquisidores debieron ser tomadas en gran estima.

La cuestión de la sede cartagenera había dado demasiados quebraderos de cabeza a la Corona española, por lo que la elección de sus obispos debía ser un tema de sumo cuidado. Si turbulento fue el gobierno de Miguel Antonio Benavides, no menos lo fue el de Antonio María Casiani, cuya pacificación llegó a ser incluso uno de los primeros encargos del recién llegado virrey Antonio de la Pedroza y Guerrero. Él mismo fue quien llevó la real cédula que ordenaba el regreso de Casiani a la península y él mismo quien anunció su muerte, con una recomendación muy particular respecto a cómo debería ser el siguiente obispo, en la misma línea que la anterior recomendación del confesor real y que recoge J. M. Pacheco en su obra:

Persona secular y de España, de buena edad, de juicio, prudencia, madurez, y de acreditadas experiencias, y de entereza y resolución y que sea de profesión letrado, y siendo posible, que haya sido provisor, porque instruido en la facultad como en la práctica a poco tiempo se enterará de los derechos municipales de estos dominios y tendrá el gobierno que se desea, porque en el infeliz y lamentable estado en que se halla esta ciudad y toda su provincia se necesita muy mucho de que sea en esta forma la providencia que tomase (el rey), la cual conviene que sea prontísima, y que se le prevenga pase luego, por la suma falta que hace el prelado en esta Iglesia. ${ }^{22}$

Podemos observar cómo la recomendación de Pedrosa iba en la misma línea que la del confesor e incluso llegaba más allá en las características que debía tener un obispo. Destacan varias cuestiones: en primer lugar la preferencia de peninsulares frente a criollos. El nuevo virrey no ocultaba su intención de que los puestos importantes en Indias recayeran en manos de peninsulares, de manera que las decisiones tomadas en Indias se suponían que deberían ser más acordes con lo dictado en la península. En segundo lugar, la importancia dada a las cuestiones de índole jurídica, debían según el virrey estar por encima de las pastorales, ya que no hace ninguna mención a ellas, condicionado por los difíciles años de pugnas jurídicas en las que se habían embarcado los obispos cartageneros, que hacían estas cuestiones las más prioritarias. Por último, llama la atención

\footnotetext{
22 Ibídem: 79. A su vez recogido en Groot 1957.
} 
cómo se refiere a la situación en la que se encontraba la ciudad, este «infeliz y lamentable estado», una sede vacante después de un gobierno turbulento volvía a Cartagena, en un momento en que las defensas de la ciudad se encontraban destrozadas y el cabildo eclesiástico se negaba a contribuir a su reedificación, por lo que resultaba importante elegir bien a un candidato que se centrara en los asuntos de gobierno de la diócesis y no levantara más polvaredas entre las autoridades peninsulares y eclesiásticas.

A pesar de lo expuesto por el confesor del rey y por el virrey Pedrosa, los puestos siguieron recayendo en personalidades con una oportuna formación, no necesariamente en cánones. El problema era encontrar un candidato dispuesto a ocupar la sede cartagenera. Si ya los obispados americanos eran poco apetecibles, menos aún lo era el de Cartagena, por la situación de la ciudad que describía Pedrosa y no parecía que se desconociera en la península. En febrero de 1719 se elegía nuevo obispo para Cartagena. En un primer momento se pensó en Manuel de la Huelga Argüelles, vicario de Toledo y visitador de la Corte, pero declinó el cargo. El primero de la terna, Dionisio Mellado, auxiliar de Toledo, también rechazó el cargo ya que no quería marchar a América, aparte de escudarse en que el obispado «estaba muy arruinado y atrasado por el gobierno pasado". ${ }^{23}$ Cartagena se dibujaba pues como un destino poco atractivo, dado que los difíciles años del principio de siglo habían convertido la ciudad en un obispado que se presentaba de difícil gobierno y pocos beneficios. El puesto recayó en el segundo de la terna, el magistral de Zamora, Don Juan Francisco Gómez Calleja, figura que cumplía con los requisitos expuestos por el virrey, además de ser peninsular y haber ejercido el cargo de provisor.

Una vez nombrados los obispos para el cargo, se procedía a la preparación del largo viaje desde la península hasta Cartagena. Un viaje costoso pues no solo viajaba el obispo sino todo un séquito de diversas personas, a lo que había que sumar los gastos de emisión de las bulas y el llamado pontifical, es decir, todos los elementos litúrgicos propios de un obispo. Por ello no es de extrañar que la práctica totalidad de los obispos pidieran una ayuda de costa para poder trasladarse a su sede. En algunos casos estos traslados podían demorarse en el tiempo, pese a ser advertidos desde la Corona de embarcarse rápidamente. Otros pedían una demora para solucionar asuntos pendientes, como ocurrió con Agustín Alvarado, abad de la colegiata de Olivares, quien primero debía solucionar unos problemas de diezmos con el arzobispado de Sevilla. Al igual que otros obispos, pidió una ayuda de costa para realizar el viaje que generalmente era sacada del ramo de vacantes de la propia catedral. En caso de que fuera insuficiente se recurría al arzobispado de Santafé o a las reales cajas. La cantidad que fue variando según las circunstancias era de 4.000 pesos.

Superados todos estos escollos llegaba el momento más esperado, la toma de posesión de la nueva sede por parte del obispo. La llegada de los obispos levantaba gran expectación en la ciudad, presentándose la oportunidad por parte de los diversos agentes de la ciudad de demostrar el papel de cada uno, por medio de toda la maquinaria

${ }^{23}$ AGI, Santa Fe, 1168. El confesor real, Madrid 17 de febrero de 1719. protocolaria. El obispo era recibido por su clero y por las autoridades de la ciudad y en la catedral se producía la toma de posesión de su cargo celebrándose la llegada con novenas y salvas. La cuestión más espinosa era la presentación a las autoridades civiles, como era costumbre, a saber, el gobernador y cabildo secular presentes a la llegada del nuevo obispo junto con el cabildo eclesiástico. Pero esto no fue siempre así, pues las cuestiones de protocolo hacían que el estamento eclesiástico entrara en conflicto con el civil, en un difícil equilibrio sobre el papel de ambos poderes. En 1776 el ayuntamiento de la ciudad se abstuvo de acudir al recibimiento del obispo Blas Sobrino, presuntamente por unas cuestiones de preeminencia a la hora de acompañar al obispo, que desataron las tensiones. El cabildo eclesiástico pretendía ir en el lugar más cercano al prelado seguido del cabildo secular, mientras el gobernador debía acompañar al obispo a la misma altura en paralelo. Aunque nos pueda parecer una cuestión de poca importancia, era un símbolo muy significativo del puesto que ocupaba cada uno en la ciudad. En este contexto se comprende la actitud del cabildo secular interesado en que desde la llegada del obispo se dejara constancia del equilibrio de poderes que debía reinar en la ciudad entre la esfera eclesiástica y civil, obispo y gobernador, que ejercían ambos una autoridad delegada del rey, aunque fuera para distintas cuestiones y una autoridad que recaía sobre las conciencias y que rebasaba el ámbito de lo civil. De hecho tampoco era una cuestión nimia para las autoridades peninsulares que frente a la queja del cabildo eclesiástico sentenciaban como debía ser el orden, obispo y gobernador en paralelo, seguidos del cabildo eclesiástico y, por último, el secular. ${ }^{24}$

Los obispos solían llegar con varios miembros de su familia, algunos criados y otros acompañantes. Por ejemplo, en 1713 el obispo Casiani viajó acompañado de dos religiosos de su propia orden y varios $\operatorname{criados}^{25}$, entre ellos Diego Rodríguez Delgado, que había sigo discípulo suyo en Alcalá de Henares. Fue secretario del obispo, le acompañó en varias visitas y obtuvo puestos de relevancia en la diócesis bajo su amparo, además de varias capellanías. Su carrera eclesiástica en Indias después de la muerte de Casiani continuó con varias prebendas en Santa Marta y posteriormente como secretario de otros obispos en sus respectivas sedes. ${ }^{26}$ No se trata del único ejemplo, el personal de acompañamiento de los distintos prelados logró, al calor de sus protectores, alcanzar puestos de relevancia en la sede como personal de confianza.

Tuvieron el papel de personal de asesoramiento $y$ compañía junto a otros del servicio personal. Especialmente fueron escogidos para ser sus secretarios primando la confianza que depositaban en personas con las que habían compartido anteriores experiencias. Constituían el círculo más cercano del prelado por lo que lo acompañaban también en los posibles cambios de sede. En cambio, no ocuparon puestos eclesiásticos dentro del cabildo, que recayeron en su mayoría en personas de la propia ciudad sin vinculación con los familiares de los obispos.

24 AGI, Santa Fe, 1055, n.5. Carta del deán y cabildo de Cartagena, 26 de febrero de 1777.

25 AGI, Contratación 5567, n. 19.

$26 \mathrm{AGI}$, Indiferente, 222, n.105. Méritos de Diego Rodríguez Delgado. Madrid, 28 de febrero de 1737. 
El último paso para muchos obispos no terminaba al llegar y tomar posesión de la nueva sede, pues como en anteriores centurias la mayoría de los prelados llegaron sin consagrar, lo cual tampoco fue un problema que les impidiera desde su llegada la toma de importantes decisiones. No obstante, la consagración era indispensable para actuar con plenos poderes episcopales, pues hasta que no la recibiera tan solo era un electo o nominado. De ahí que se pusiera tanto interés en agilizar las consagraciones, y en algunos casos, la Corona pudiera utilizar este hecho como medida de presión. El caso más claro fue el de Antonio María Casiani, obispo incansable en la defensa de sus ideas, que recordaba a su predecesor en el cargo, Miguel Antonio Benavides. El obispo llegó sin consagrar y solo logró ser consagrado en 1716, casi tres años después de su llegada y sólo con la condición impuesta por su clero, el gobernador y los obispos presentes, de templar y moderar sus disputas. ${ }^{27}$ En otros casos, para evitar situaciones inestables durante las sedes vacantes derivadas de la falta de la autoridad episcopal, la Corona prefería que los obispos partieran lo más rápido posible hacia su sede evitando de esta manera alargar las vacantes, como se lo hizo entender la Corona a Gómez Calleja. Otra solución era la consagración en España, como hizo Martínez Garrido con la condición de partir hacia América a la primera oportunidad. La misma fórmula siguieron Blas Sobrino y Miguel Álvarez Cortés. Este problema era menos complejo con los obispos de procedencia americana, puesto que algunos recibieron su consagración en la ciudad de proveniencia: Bernardo de Arbiza en Panamá y Manuel de Sosa Betancourt en Caracas. Los obispos cartageneros recibieron su consagración en la misma provincia: Bartolomé Narváez lo hizo en Barranquilla por medio del obispo de Santa Marta y Jerónimo Liñán en el obispado de Panamá.

\section{CARACTERÍSTICAS DE LA SEDE CARTAGENERA}

No obstante, el nombramiento de los distintos sujetos estuvo condicionado por las características de la sede cartagenera. Destacaron las largas sedes vacantes a lo largo de todo el periodo colonial y solo a finales de siglo XVIII hubo un cambio de tendencia. Durante el siglo XVI y especialmente en el XVII, las vacantes fueron muy extensas y continuadas. La sede vacante ocupó un tercio de los años comprendidos entre la fundación del obispado y la llegada del obispo Casiani en 1714, dando una suma de unos 70 años de vacantes repartidos entre las diecinueve que hubo, de los cuales más de la mitad se corresponden con las once vacantes del siglo XVII. ${ }^{28}$ Estos largos periodos de vacantes se redujeron durante el siglo XVIII, aunque no se pudo evitar algunas vacantes largas. Hubo doce sedes vacantes desde la muerte del Antonio Casiani en 1717 hasta el nombramiento de Jerónimo Liñán en 1796, dando un valor aproximado de unos 23 años de sede vacante, a los que se podría sumar los cinco años del obispado de Diego Martínez Garrido que no estuvo presente. A la vista de los datos reflejados en el gráfico 3 se puede comprobar cómo los periodos de vacantes del siglo XVIII fueron más reducidos frente a los de

\footnotetext{
27 Pacheco 1986: 76.

28 Molino García 1975.
}

las centurias anteriores, aunque de una manera más tímida.

Las causas que provocaron las numerosas y extensas vacantes fueron distintas, algunas de ellas provenientes de la realidad de la diócesis. Pero aún mayores fueron los problemas derivados de estas vacantes.

El tiempo de permanencia de los obispos en la sede cartagenera siguió en el siglo XVIII la misma tendencia que en siglos anteriores, perfilándose Cartagena como sede de transición. Fueron muy pocos los obispos que terminaron sus días en la ciudad, ya que la mayoría de ellos partió hacia otros obispados. De los doce obispos sólo cuatro murieron como obispos de Cartagena, ya que el obispo Diego Antonio Valenzuela nunca llegó a tomar posesión de la sede al morir sin recibir las bulas. ${ }^{29}$ Por otro lado, hay que tener en cuenta que Manuel Sosa Betancourt pidió el traslado a otro obispado, pero no pudo lograrlo debido a que la muerte le alcanzó poco antes de recibir las bulas que lo destinaban al arzobispado de Santafé. ${ }^{30}$ Por tanto, solo tres obispos murieron en la cátedra de Cartagena, el primero del siglo XVIII Antonio María Casiani y es significativo que el resto solo fueran los cartageneros Bartolomé Narváez Berrio y Jerónimo Liñán y Borda.

Como causa principal para la renuncia al obispado, los distintos prelados, al igual que sus predecesores de los siglos XVI y XVII, culpaban al clima de la zona como principal causante de enfermedades que machacaban la salud. Fue la causa más esgrimida pero no la única, pues las relaciones con el clero de la diócesis también hicieron que algunos prelados solicitaran un cambio de sede. Hasta el momento, los estudios han puesto en relevancia el aspecto económico ${ }^{31}$, que evidentemente debía pesar a la hora de promocionar a mejores obispados. Conocido es que las rentas de la diócesis de Cartagena no eran importantes frentes a otros obispados dentro del virreinato como Quito o Santafé. Sin embargo, no podemos obviar otros aspectos, que en numerosas ocasiones debieron ser determinantes.

El caso del obispo Francisco Gómez Calleja es una muestra de los problemas a los que se tenían que enfrentar las diócesis, debido a los numerosos traslados. Podían surgir problemas de jurisdicción, enfrentamientos con los miembros del cabildo, y lo que fue común a todas las vacantes, dejar el gobierno de la diócesis en manos del cabildo eclesiástico. Uno de los momentos más delicados surgía a la hora de declarar la sede vacante. La dificultad de los viajes por la geografía neogranadina, unido a los achaques de salud y distancias entre ciudades, podían crear situaciones en las que los obispos una vez nombrados para otra diócesis no pudieran trasladarse y provocaran problemas de jurisdicción. Gómez Calleja aunque renunciara a la sede de Cartagena por la de Popayán nunca abandonó la primera. El obispo se hallaba en una situación difícil, pues había sido nombrado prelado de Popayán pero no podía trasladarse a ella. No sabemos con certeza si solicitó el traslado a la sede de Popayán por problemas relacionados con el clima cálido de Cartagena, pero se puede comprender este motivo, ya que el cambio por zonas más templadas era

29 Pacheco 1986: 165

30 Ibídem: 168.

31 Los diezmos en Cartagena nunca llegaron a ser abultados, tanto por ser el comercio la principal actividad económica como el estancamiento de la producción agraria. Meisel Roca 2005: 72. 
algo habitual. Las causas para renunciar al traslado sí están claras, pues es el mismo obispo es quien las expone para justificar su rechazo, a saber, la enfermedad que sufría, a lo que se unía la dificultad y peligro del viaje a tierras tan lejanas. El problema era que el obispo ya había recibido las bulas que lo convertían en obispo de Popayán, mientras para Cartagena también había sido ya nombrado un sustituto en la figura de Manuel Antonio Gómez de Silva.

Estos hechos provocaron una situación anómala, pues la sede quedaba vacante desde el momento en el que su obispo era preconizado por el papa para otro obispado. El cabildo eclesiástico debía proceder a declarar la sede vacante y a elegir vicario general del obispado. No obstante, había varios canonistas que aseguraban que la sede primera no quedaba vacante, por lo menos mientras el obispo no tomara posesión de otra sede. Así lo comprendió el obispo Gómez Callejas, pues le comunicaba a su cabildo que todavía no había perdido su jurisdicción sobre la sede cartagenera ni tampoco los derechos sobre las rentas del obispado. ${ }^{32}$ Esta situación enfrentó a obispo y cabildo catedral contra el cabildo secular, que reclamaba los derechos sobre las rentas de la sede vacante, aplicados por el rey a las fortificaciones de Cartagena. La situación creada incluso llegó a romper la armonía dentro del propio cabildo eclesiástico pues el arcediano no reconoció a Gómez Calleja como obispo sino a su sustituto Manuel Antonio Gómez de Silva. Finalmente volvió a recibir bulas nombrándolo obispo de Cartagena de nuevo, pero ya había fallecido cuando las recibió. ${ }^{33}$

En esta situación podemos ver dos circunstancias que condicionaron el gobierno de los obispos cartageneros, por un lado los problemas de salud, y por otro, las relaciones con su cabildo. En este caso el obispo contó con el apoyo de su cabildo, a pesar de que encontrara oposición en alguno de los prebendados. Sin embargo, no siempre fue así pues las relaciones de los obispos con su cabildo fueron también una causa importante para que pidieran un cambio de sede.

En cuanto a los problemas de salud, eran esgrimidos como principal causa para reclamar un traslado, especialmente tras realizar las largas visitas por las zonas pantanosas y agrestes de la diócesis. Así ocurrió con Sosa Betancourt quien tras recorrer la diócesis en visita pastoral en febrero de 1764, tuvo que retirarse al poblado de El Bosque en las afueras de Cartagena a descansar. Achacaba males relacionados con el clima húmedo de la zona y la cantidad de insectos que le habían llagado las piernas. La adaptación al clima tropical no debió ser fácil para unas personas que provenían de climas más templados, a pesar de que en este caso hubiese pasado varios años en Caracas. La visita debió suponerle un esfuerzo agotador, pues suplicaba que lo sacasen de «este purgatorio, aunque mejor diría infierno, según lo que se expresa». Defendía también el obispo su traslado exponiendo que era el sufragáneo más antiguo del arzobispado de Santafé y de todos los alrededores, por lo que reclamaba la vacante del mismo arzobispado santafereño ${ }^{34}$, peticiones que como sabemos fueron confirmadas demasiado tarde.

32 AGNCO, Curas y obispos, 14 d.15 Carta del obispo Gregorio Gómez Calleja al cabildo eclesiástico. Cartagena, 3 de junio de 1726.

33 Pacheco 1986: 81-84.

34 AGI, Santa Fe, 967. Carta del obispo Manuel Sosa Betancourt a D. Julián de Arriaga y Rivera, Cartagena 4 de abril de 1764.
De igual modo se expresaba su sucesor Diego de Peredo quien desde 1769 fue solicitando el traslado a otra diócesis por motivos de salud causados por el clima tropical. Al igual que su sucesor gran parte de los males los achacaba a las visitas pastorales. Solicitó el traslado en tres ocasiones, en julio de 1769, en noviembre del mismo año y finalmente en abril del siguiente, adjuntando a su petición un certificado médico con un diagnóstico claro: los pruritos y los dolores de cabeza provenían del clima cálido. ${ }^{35}$ No obstante, a la enfermedad y cansancio del obispo se le unió otra causa por la que solicitar el cambio, quizás más fuerte todavía. Las relaciones del obispo Peredo con su cabildo habían ido empeorando por haber querido él mismo presidir como ordinario los cabildos de la hermandad de San Pedro, formada por los miembros del cabildo eclesiástico. Las tensas relaciones con su cabildo se pusieron de manifiesto cuando le fue concedido el traslado al obispado de Yucatán con fecha de julio de 1770. Sin embargo, no había dejado el gobierno de la diócesis en manos de su cabildo y de nuevo podía repetirse el caso anterior del obispo Gómez Calleja. En esta ocasión el obispo no contó con el apoyo de su cabildo, quien por el contrario arremetió contra él, acusándole de mantener una continua discordia con todos los estamentos de la ciudad, clero secular, religiosos y gobernador. El cabildo intentó acordar con el obispo su permanencia en el gobierno de la diócesis siempre y cuando este declarase la sede vacante. Peredo pretendió ganar un poco de tiempo trasladando la decisión sobre la vacante al Consejo, quien le negó la declaración de sede vacante pues su nombramiento para Yucatán no había sido oficial ya que sólo fue anunciado por el apoderado del obispo en Madrid. Finalmente el obispo consiguió salir para su nueva sede en ese mismo año. ${ }^{36}$

Así pues, no solo era el clima caluroso lo que pesaba sobre la vida de los prelados cartageneros sino que también los litigios y enfrentamientos con las autoridades civiles y con los propios miembros del clero eran motivo para solicitar el traslado. Una vez concluida la dificultosa visita de José Díaz de la Madrid, solicitaba en febrero de 1781 un cambio de sede después de haber servido con todas sus fuerzas en la diócesis de Cartagena:

Como en la mayor parte ha sido preciso hacer frente a la relajación, me he concitado muchos enemigos, que siendo contra uno solo, y destituido de protección y sombra, no les ha sido difícil triunfar, consiguiendo que el Consejo y Audiencia de Santafé, me desaíren frecuentemente. En estas circunstancias ocurro a la piedad de V.S.I. suplicándole humildemente se digne destinarme otro báculo, siquiera para que logre la quietud de mi conciencia, el reposo de mi espíritu y salvación de mi afligida alma.

Y si esto no mereciese podrá V.S.I. disponer de esta Mitra, con reflexión a que si V.S.I. también me desampara, mejor me estará el retiro de una pobre celda, donde dedicado todo a Dios, tenga lugar de pedirle prospere a V.S.I. en las mayores felicidades, y que después nos conceda a ambos su eterna amable vida. ${ }^{37}$

35 AGI, Santa Fe, 1044, n.12. El obispo de Cartagena pide ser trasladado a otra ciudad, 28 de abril de 1770.

36 AGI, Santa Fe, 1047, n.14. Expediente de haber querido el obispo presidir como ordinario los cabildos de la hermandad de San Pedro, Cartagena 1773.

37 AGI, Santa Fe, 1171. El obispo Fr. José Fernández de la Madrid al arzobispo confesor Fr. Joaquín de Eleta. Cartagena, 6 de febrero de 1781. 
El celo pastoral del obispo Díaz de la Madrid había hecho que no contara con muchos apoyos, especialmente dentro de su propia catedral, pues, en numerosas ocasiones, les fue difícil a los prelados doblegar el ánimo e intereses del cabildo eclesiástico. Es de destacar hasta qué punto este tipo de situaciones podían enrarecer el clima dentro del propio clero, pues hicieron que el obispo pidiera la renuncia a su mitra. Sin embargo, no hay que dejar de lado la temporalidad de la mitra cartagenera, pues el obispo Díaz de la Madrid, como la mayoría de sus antecesores, prefirió un cambio de sede antes que terminar sus días como pastor cartagenero. Es difícil establecer hasta qué punto fue determinante el clima enrarecido dentro del propio cabildo y los desaires de las autoridades civiles para hacer que solicitara la renuncia, no obstante, hay que tener en cuenta que las relaciones de los prelados con las autoridades civiles y demás miembros del clero, fueron para la mayoría de los obispos tensas. La humildad mostrada por el obispo Díaz de la Madrid al solicitar una celda conventual, en el caso de no merecer otra mitra, no deja de ser un recurso habitual a la hora de pedir un traslado, más propio de recurso retórico que de un verdadero deseo. En carta de enero de 1785 pedía de nuevo esta vez al arzobispo-virrey Caballero y Góngora que intercediera para que se le trasladara a otra sede. Entre los motivos volvía a remitir al clima caluroso y la falta de apoyo que encontraba entre los prebendados con los que había tenido diversas causas legales. ${ }^{38}$ Años más tarde, en 1792, se accedió a hacer efectivas las peticiones del obispo, siendo trasladado a su sede natal de Quito, con lo que podemos comprobar que precisamente no se trató de una celda monástica. Es difícil determinar por tanto, qué empujó de manera más decisiva a estos prelados a solicitar el cambio de sede, pues si bien es cierto que el clima no era favorable, las relaciones con el cabildo podían ser una causa suficientemente importante para elegir un cambio de aires.

En cuanto al cambio de sede, la Corona se decantó por los obispados del interior. Tres de ellos fueron trasladados al obispado de Quito, dos a Santafé y el resto a distintos obispados como Trujillo, Charcas, Popayán o Yucatán. Para muchos de estos obispos no fueron estos traslados los únicos, sino que estas sedes también fueron provisionales pues de ellas pasaron a otras, aunque fueron casos más contados debido a la avanzada edad con la que conseguían el acceso al obispado.

Sin duda la situación económica de la sede cartagenera, fue un aspecto determinante, pues la escasez de rentas motivaba que los obispos optaran a una sede con beneficios más altos. Cartagena, en comparación con obispados cercanos, tenía unas rentas que sin ser muy altas eran superiores a otros obispados de la zona, por lo menos respecto a Santa Marta. Si tenemos en cuenta los obispados a los que son trasladados los prelados cartageneros, vemos que en la mayoría de los casos fueron destinados a otros con rentas muy superiores, como los de Quito ${ }^{39}$ o Santafé.

\footnotetext{
38 AGNCO, Contrabando, t 4, fol. 251. En Martínez Reyes 1986: 551.

39 Núñez Roldán 1993. Según el autor «la diócesis de Quito, sufragánea de Lima, era según un informe elaborado por el Consejo a la muerte del obispo Nieto Polo una de las más principales del Reino del Perú, por su influencia política - compartida con una Audiencia- y por sus rentas, calculadas en 24.000 pesos anuales» (ibídem: 332).
}

Sin embargo, otros obispados tenían unas rentas inferiores, además de ser sedes con una influencia religiosa inferior, como el caso de Popayán y que compartían con Cartagena ser sede de primer destino. ${ }^{40}$

En una consulta a Cámara para proveer el obispado de Quito se debatió la conveniencia de elegir para esa sede obispos de otras inferiores, debido a la importancia del obispado. En la respuesta del rey a dicha consulta, se declaraba partidario solo de que los traslados se realizaran por causas justificadas de salud o por razones del clima. ${ }^{41}$ El debate entablado entre Cámara y rey por el traslado de los obispos, muestra una situación que debió hacerse costumbre, la constitución de una jerarquía de sedes donde la cúspide estaría ocupada por sedes de primer orden ocupadas por obispos con experiencia previa como prelados, como serían las sedes metropolitanas o aquellas de mayor importancia económica y religiosa. Detrás quedarían unas sedes de transición o promoción, que serían el primer destino de muchos prelados desde donde optarían a otros puestos diocesanos. En estas sedes los obispos debían adquirir experiencia en el gobierno de sus diócesis acumulando méritos que les sirvieran para optar a la promoción. Quedarían pues en estos obispados aquellos prelados que perdieran su vida en el ejercicio de sus funciones o cuyos méritos no fueran recompensados por la Corona. En el caso de Cartagena se confirma esta tendencia. Ninguno de los obispos provenía de otra sede diocesana, y Cartagena se convirtió para muchos de ellos en el trampolín para acceder a otros obispados, si bien es cierto que no todos solicitaran ese traslado, decisión que dependería de las metas personales de cada uno.

De los diez obispos que solicitaron el cambio de sede, solo cuatro lo hicieron por razón de enfermedad, pues para el resto no quedan claras las causas por las que fueron removidos de su sede. Este tipo de alegaciones confirma la tendencia de la Corona a satisfacer los traslados, aunque no deben ser descartadas otras opciones. Los obispos que esgrimieron problemas de salud parecen estar bien justificados, pues para ello y para evitar posibles fraudes solían acompañar sus solicitudes con informes médicos que corroboraran la enfermedad. Por tanto, no debemos menospreciar esta situación pues el clima de la zona verdaderamente debió ser un suplicio para los europeos, especialmente para aquellas personas que no estaban acostumbradas al esfuerzo físico y a condiciones de vida poco cómodas. Para los obispos, personas acostumbradas a vivir entre las comodidades de los claustros de sus conventos o en casas señoriales con todas las comodidades, las visitas de la gobernación tuvieron que ser muy duras, ya que de hecho tras estas visitas era cuando se producían las quejas por enfermedad. Clarificador es el caso del obispo cartagenero Bartolomé Narváez quien encontró la muerte realizando la visita pastoral en la región del Sinú en febrero de 1754, siendo enterrado en Lorica. ${ }^{42}$ También podemos

40 Popayán fue también una sede secundaria donde obispos de origen criollo comenzaron una importante carrera eclesiástica, Gálvez Peña 2012: 114.

41 Núñez Roldán: 314. P. Núñez Roldán utiliza el término de diócesis de "acceso y salida» para referirse a Cuba, diócesis en la que la mayoría de los obispos dejaban el cargo para dirigirse a otros obispados.

42 Pacheco 1986: 181. 
tener en cuenta el caso del obispo Gómez Calleja que tuvo que renunciar debido a sus problemas de salud, a los que tuvo que enfrentarse por una difícil enfermedad, pues incluso pedía por carta al rey poder firmar con estampilla ya que los temblores le impedían hacerlo con la mano. ${ }^{43}$ Baste decir que no solo los obispos sufrieron los rigores del clima en las duras visitas de su obispado, sino también las personas que les acompañaban. Ejemplo de ello es el relato del obispo fray José Díaz de la Madrid que realizó tras su visita:

Ya por lo ardiente del clima que sofoca y desalienta aun a los irracionales, ya por la malignidad de los temperamentos, ya por la escasez de alimentos en algunos parajes y ya por lo salobre o cenagoso de las aguas en otros, habiéndose agravado en sumo grado mis aflicciones con el lastimoso acaecido de haber perdido la vida mi capellán, el P. Lector, Fr. Pedro de Nava, al terminar la primera parte de mi peregrinación y en la segunda, mi secretario D. José de Vargas Machuca, que quedó sepultado en el sitio del Corozal. ${ }^{44}$

Por tanto, parecen justificadas las solicitudes de los prelados por cambiar de sede. De hecho las descripciones del clima de Cartagena que nos dejan los viajeros y científicos, hablan de la difícil aclimatación de los europeos al clima tropical. La humedad y el fuerte calor hacían que los recién llegados sudaran en exceso, hablándose incluso de la pérdida de pigmentación en la piel, de modo que podemos pensar que estos tenían que agravarse más en los obispos, debido a las ropas propias de su estado, que por lo menos públicamente debían llevar. ${ }^{45} \mathrm{~A}$ esta realidad hay que sumar la avanzada edad a la que los obispos llegaban a sus sedes, aspecto que no ha pasado por alto la historiografía y que llega a explicar el «abundante necrologio de algunos obispados ${ }^{46}$, del que no se pudo zafar el cartagenero.

$\mathrm{Si}$ analizamos los gobiernos de los obispos en siglos anteriores, los datos son semejantes, contando con que en 1548 Francisco Santamaría Benavides renunció al cargo por motivos de salud. Pero el siglo XVII fue mucho peor en este aspecto, pues muchos obispos murieron por enfermedades achacadas al clima tropical: Pedro de Vega (1616), Diego de Torres Altamirano (1621), Diego Ramírez de Cepeda (1629), Cristóbal Pérez de Lazárraga (1648) y Francisco Rodríguez de Valcárcel (1651). Aunque no hay que desestimar las pretensiones de puestos de mayor importancia o mayores rentas, parece claro que el clima jugó un papel importante en hacer de Cartagena una sede de paso.

No obstante, a la vista de los datos del gráfico 3, el traslado de sede no condicionó la duración de las vacantes, sino más bien la muerte de los obispos y el tiempo en ser provisto el puesto. Así pues, podemos comprobar cómo en el siglo XVI, periodo en el que se produjeron extensas vacantes, solo cuatro obispos solicitaron el traslado. Más significativos son los datos del siglo XVII, periodo de mayor duración de las vacantes, en el que solo se produjeron tres traslados de sede. El siglo XVIII es el que más traslados de

43 AGNCO, Curas y obispos, 44 d.6, El obispo pide firmar con estampilla. Cartagena, 1728.

44 AGI, Santa Fe, 1171. Carta del obispo Fr. José Díaz de la Madrid al arzobispo D. Fr. Joaquín de Eleta, Cartagena 6 de febrero de 1781.

45 Ulloa y Ulloa 1748: 58, n. 94.

46 Egaña 1966: 1050. sede vivió y en cambio, con sedes vacantes más reducidas. También es inevitable observar cómo los traslados de sede fueron más comunes entre los obispos pertenecientes a la rama secular. Si bien es cierto que durante los primeros siglos la presencia de seculares fue muy reducida y que muchos obispos regulares solicitaron el traslado y no les fue concedido, los datos son muy evidentes. Si los comparamos con datos totales para toda América, podemos concluir que fue una tendencia general de los obispos seculares. El siglo XVIII fue el periodo donde se produjo la mayor movilidad de obispos, sin estar relacionado con la incorporación de criollos a las mitras americanas, se debió en gran parte al aumento de obispos pertenecientes al clero secular. ${ }^{47}$ Corrobora este dato el caso cartagenero, pues la solicitud de traslado fue indistintamente solicitada tanto por los obispos de origen peninsular como criollo.

GRÁFICO 3

Evolución de los periodos de las sedes vacantes y renuncias por origen eclesial

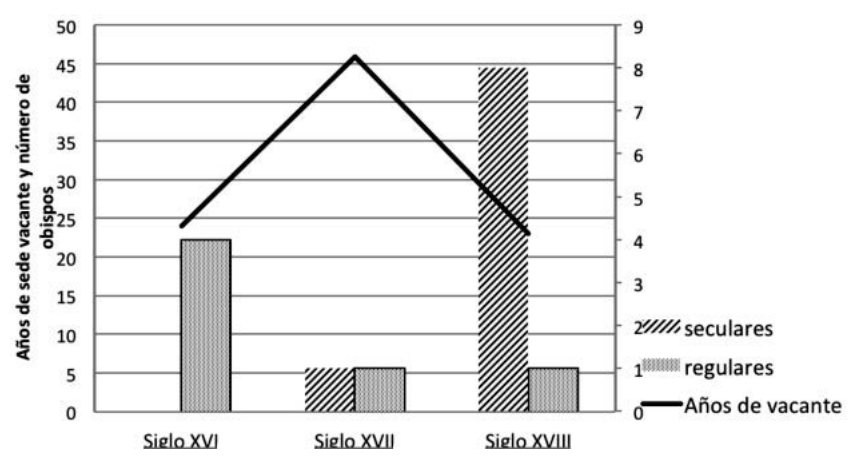

Fuente: AGI, Santafé, diversos legajos.

Esta situación de numerosas vacantes se vio agravada por los abundantes casos de obispos «imposesos», es decir, aquellos ya nombrados que no llegaron a tomar posesión del obispado, de los que hubo varios durante la primera mitad de siglo. Desde 1713 hasta 1755 de los diez obispos que fueron nombrados para Cartagena, cinco de ellos no tomaron posesión de la sede por distintos motivos. El primero de ellos fue don Juan de Layseca y Alvarado, inquisidor del tribunal de Cartagena, nombrado en Cámara en abril de 1713, aunque puede que ni siquiera le llegara el nombramiento, pues cuando llegó en agosto el electo de Popayán, fray Antonio Casiani, encontró al inquisidor fallecido, teniendo que asumir él mismo el obispado. ${ }^{48} \mathrm{El}$ siguiente fue Antonio Manuel Gómez de Silva, designado en última instancia obispo de Popayán en 1728, como le ocurrió a Jacinto Aguado Chacón, que antes de ser preconizado fue trasladado a la sede de Arequipa. Diego Antonio Valenzuela Fajardo fue presentado para Cartagena en noviembre de 1754, pero cuando llegaron las bulas ya había muerto en su ciudad natal de Bogotá. ${ }^{49}$ A diferencia de los anteriores, Diego Martínez Garrido fue consagrado como obispo de

47 Castañeda Delgado y Marchena Fernández 1992: 240 y ss.

48 AGI, Santa Fe, 1169. Consulta de Cámara, 9 de abril de 1713.

49 Pacheco 1986: 165. 
Cartagena pero nunca llegó a su sede. Fue presentado en noviembre de 1740 , recibió sus bulas en noviembre del siguiente año, tras conseguir el permiso para consagrarse en la península, pero diversas causas le impidieron el embarque para Cartagena siendo la más importante la guerra entre España e Inglaterra. En junio de 1745 ordenaba el rey que no se le entregaran a su apoderado sus rentas episcopales hasta que no se presentara personalmente en su diócesis. Por este motivo piensa J.M. Pacheco que el obispo nunca llegó a su diócesis. ${ }^{50}$ Este dato queda confirmado con la petición que realizó el mismo obispo al rey, en ella solicitaba que se le devolvieran los frutos y rentas del obispado de Cartagena, pues aunque no hubiese acudido personalmente a él, sí lo gobernó por medio del deán, debido a la imposibilidad de acudir por motivo de la guerra. ${ }^{51}$ Así pues, la diócesis fue dirigida por un gobernador nombrado por el mismo obispo en la distancia, que primero recayó en el deán Sebastián Petrel y desde 1746 en el siguiente deán Pedro de Vivanco y Moncayo, quien tuvo como asesor al abogado José Ignacio González. ${ }^{52}$ En agosto de 1746 Martínez Garrido fue nombrado titular del obispado in partibus de Tricala, cargo honorífico con jurisdicción sobre los lugares sujetos a la orden militar de Santiago. ${ }^{53}$

Estos datos explican que la mayoría de las vacantes se desarrollaran en los primeros años de siglo, situación que logró la Corona reducir evitando los traslados de diócesis, si no era por cuestiones de salud, de manera que para la segunda mitad del siglo, ninguna vacante superó más de dos años. Sin embargo, la principal causa de esta reducción fue el aumento de obispos de origen americano, lo cual permitía la disminución del tiempo entre el nombramiento y el traslado a la sede, tiempo que se reducía aún más, cuando los elegidos eran de la misma ciudad. Los continuos traslados y defunciones en siglos precedentes, hicieron que la diócesis estuviera en una casi vacancia permanente, con lo cual el gobierno de la sede se hacía casi imposible, dejándolo en manos del cabildo y sometido a continuos vaivenes de obispos que se tenían que esforzar por adecuarse a las particularidades de su nueva iglesia y clero. En estas situaciones difícilmente se podían llevar a cabo una continuada pastoral y control del clero, dedicado tanto a la administración de los sacramentos como a la evangelización por medio de las doctrinas.

La segunda mitad del siglo XVIII, consiguió romper esta tendencia, ya que haber reducido los periodos de vacantes dotó a la diócesis de mayor estabilidad y agilidad en su gobierno. La mayor presencia de los obispos en sus sedes

\footnotetext{
50 Pacheco 1986: I, 174.

51 Biblioteca Histórica. Universitat de València. El obispo Diego Martínez Garrido al rey.

52 AGNCO, Curas y obispos, 20 d. 57. Don Ignacio González satisface a la queja que dice que puede haber dado el obispo de Cartagena contra su proceder, 13 de noviembre de 1753 . En el auto que le sigue, aunque el deán Pedro de Vivanco firmara como gobernador del obispado durante el gobierno de Diego Martínez Garrido, en los testimonios a favor del abogado Ignacio González la mayoría de los testigos se refieren a todos los obispos durante los cuales colaboró sin nombrar expresamente a Diego Martínez Garrido. En cambio, cuando debieran referirse al gobierno de Diego Martínez Garrido siempre lo hacen refiriéndose al gobierno del provisor y gobernador Pedro Vivanco, lo cual nos puede llevar a la conclusión de que el obispado fue regido por este deán.

53 Restrepo Posada 1955: 313.
}

restaría poder al cabildo que en periodos de sede vacante o ausencia de los prelados actuaban con más independencia. Al mismo tiempo los enfrentamientos entre miembros del cabildo tendieron a reducirse o por lo menos a concentrarse en asuntos particulares, pues la presencia del obispo ponía orden en el capítulo catedralicio. Y es que las sedes vacantes conllevaban situaciones muy difíciles de solucionar, pues los miembros del cabildo pocas veces podían estar de acuerdo a la hora de nombrar un gobernador que agradara a todos, y que pudiera poner orden y respeto entre iguales. Esta situación fue también difícil de dirimir para la Corona y los sínodos americanos, pues fue un tema que estuvo pendiente de solución durante todo el periodo colonial, a saber, cómo gobernar y dirigir las sedes vacantes al margen de las rivalidades y tensiones entre los miembros de los cabildos.

\section{CONCLUSIONES}

Podemos definir tres aspectos como características fundamentales del episcopado cartagenero durante el siglo XVIII: el criollismo, la importancia del clero secular y mayor eficiencia en el control y gestión de los asuntos diocesanos.

El obispado de Cartagena se presenta para el siglo XVIII como un obispado de paso, tanto por sus características climatológicas como económicas. A pesar de que la ciudad vivió durante esta centuria un importante impulso económico, este no repercutió en las rentas eclesiásticas, nutridas especialmente de los diezmos. La principal actividad económica de la ciudad fue el comercio, por lo que las rentas eclesiásticas no se beneficiaban de ella, permaneciendo el obispado de la ciudad con unas rentas poco apetecibles frente a otros obispados. No obstante, sí permitió la aparición de importantes familias de comerciantes que pudieron mandar a sus hijos a los colegios santaferreños. El continuo ir y venir de obispos favoreció la aparición de un cabildo eclesiástico fuerte, acostumbrado a actuar sin la autoridad del pastor. Unido a las características económicas de la ciudad, pues la mayoría de sus miembros provenían del sector comercial, lo convirtió en el órgano de representación del clero criollo.

El origen secular y americano de los obispos se tiene que relacionar con el auge del criollismo que, formado en los colegios americanos, reclamaba una salida laboral acorde con los estudios realizados. Cartagena no fue ajena a estos hechos, sino que además fue un ejemplo destacado de la promoción criolla, con la aportación de cuatro obispos criollos formados en su cabildo eclesiástico. Los cambios que se operaban en el sector eclesiástico eran un reflejo de los cambios sociales del final de la colonia. La importancia del criollismo tuvo se máxima representación en unos cabildos eclesiásticos compuestos por clero criollo que se convirtieron en cantera para los obispados americanos de segundo orden, como era el de Cartagena. De forma paralela al crecimiento del clero criollo, se fue fortaleciendo el clero secular, frente a unas órdenes religiosas que entraban en franca decadencia. ${ }^{54}$ No solo se iban a ver desprovistas de numerosas doctrinas sino que también cada vez más 283

54 Sobre la relación entre clero criollo y secular ver: Lavallé 1992: 
aparecían relegadas de los obispados. Como hemos podido comprobar el aumento del clero criollo va parejo con el origen secular de los obispos, medidas favorecidas desde la Corona que gestionaba los nombramientos. Sin dejar de lado un lógico aumento del clero local que buscaba salidas profesionales, no se puede obviar que fue una tendencia favorecida desde la Corona enmarcada dentro de los planes regalistas. El clero secular formado en seminarios parecía más permeable a las doctrinas regalistas, frente a los clérigos regulares. Al mismo tiempo se lograba dotar a las diócesis de mayor estabilidad al reducir los periodos de vacantes al elegir a sujetos de la propia América, reduciendo no solo los costos de traslados sino también los tiempos de presentación. En consecuencia se racionalizaba la gestión de una institución de suma importancia cuyas largas sedes vacantes podían acarrear problemas entre el cabildo y las autoridades civiles.

El nombramiento de obispos americanos, para nada supuso un freno al regalismo y la intervención de la Corona en los asuntos eclesiásticos; es más, en el caso cartagenero, no fueron los obispos criollos los más combativos. Los principales quebraderos de cabeza para la Corona, tuvieron como protagonistas a prelados de origen peninsular, cuya actuación ponía en entredicho al Patronato. El resto de obispos en su mayoría criollos, incluso hijos de la propia Cartagena, aceptaron el regalismo como algo natural.

Bien distinto era el resto de clero de origen criollo, la Corona a pesar del fuerte regalismo no pudo hacer nada por frenar el auge de las élites criollas, que tuvieron gran protagonismo en la centuria siguiente con el comienzo de los primeros pasos emancipadores. En este sentido también tuvo un papel destacado el clero cartagenero y sus prelados. Muchos clérigos apostaron por la emancipación a pesar de la línea españolista de sus prelados, en este sentido no se puede pasar por alto que el principal clérigo patriota que defendió la independencia, el cartagenero Juan Fernández de Sotomayor, fuera educado en el seminario de Cartagena y tuviera una relación con los miembros del cabildo eclesiástico, llegando a ser el primer obispo del periodo republicano.

\section{FUENTES}

Archivo General de Indias:

Santa Fe, 967, 1044, 1047, 1049, 1055, 1168, 1169, 1171.

Indiferente, 220, 222.

Contratación, 5567.

Archivo General de la Nación de Colombia:

Curas y obispos, 14, 44, 20.

Contrabando, 4.

Universitat de València: BH. Var. 052(07)

\section{BibliografíA}

Alcedo, A. de 1786. Diccionario Geográfico histórico de la Indias Occidentales. Vol. I. Madrid.

Borrego Plá, M.a del C. 1983. Cartagena de Indias en el siglo XVI. Sevilla: EEHA-CSIC.

Castañeda Delgado, P. y Marchena Fernández, J. 1992. La jerarquía de la Iglesia en Indias: el episcopado americano. 1500-1850. Madrid: MAPFRE.

Castillo Mathieu, N. 1998. Los gobernadores de Cartagena de Indias 1504-1810. Bogotá: Academia Colombiana de la Historia, vol. 152.

Colmenares, G. 1989. Relaciones e informes de los gobernantes de la Nueva Granada. Tomos I-II. Bogotá: Biblioteca Banco Popular.

Cortés Peña, A. L. 2000. "Rasgos del episcopado español del Antiguo Régimen", en La pluma, la mitra y la espada: estudios de historia institucional en la Edad Moderna: 155-198. Madrid: Marcial Pons.

Egaña, A. de (S. J.) 1966. Historia de la Iglesia en la América española: desde el descubrimiento hasta comienzos del siglo XIX: Hemisferio Sur. Madrid: Biblioteca de Autores Cristianos.

Gálvez Peña, C. 2012. «Obispo, financista y político: el doctor don Feliciano de Vega y Padilla (1580-1641)». Histórica 36 (1): 97-133.

Groot, J. M. 1957. Historia eclesiástica y civil de Nueva Granada. Bogotá: Ministerio de Educación Nacional.

Hera, A. de la 1992. Iglesia y Corona en la América española. Madrid: MAPFRE.

Lavallé, B. 1992. "La criollización del clero», en P. Borges, Historia de la Iglesia en Hispanoamérica y Filipinas: I, 281-298. Madrid: Biblioteca de Autores cristianos.

Martínez Reyes, G. 1986. Cartas de los obispos de Cartagena de Indias durante el periodo hispánico 1534-1820. Medellín: Zuloaga.

Meisel Roca, A. 2005. «¿Situado o contrabando? La base económica de Cartagena de Indias y el Caribe neogranadino a fines del siglo de las luces», en H. Calvo Stevenson y A. Meisel Roca (eds.), Cartagena de Indias en el siglo XVIII: 72. Cartagena de Indias: Banco de la República.

Molino García, M. P. 1975. La sede vacante en Cartagena de Indias, 1534-1700. Sevilla: Escuela de Estudios Hispanoamericanos.

Nuñez Roldán, P. 1993. «Don Pedro Ponce y Carrasco obispo de Cuba y Quito (1747-1745)", en Huelva y América: actas de las XI Jornadas de Andalucía y América: 309-359. La Rábida: UNIA.

Pacheco, J. M. (S. J.) 1986. "Historia eclesiástica de Colombia», en Historia Extensa de Colombia, vol. XIII, tomos 3 y 4 (Libros I-II). Bogotá: Lerner.

Restrepo Posada, J. 1955 «Cronología de los obispos de Cartagena de Indias». Boletín Historia Antigüedades 42 (487-488): 301-320.

Ritzler, R y Sefrin, P. 1952. Hierarchia Catholica Medii et Recentoris Aevi. Vol. V (1667-1730). Patavii: II Mesaggero di S. Antonio.

Ritzler, R. y Sefrin, P. 1958. Hierarchia Catholica Medii et Recentioris Aevi. Vol. VI (1730-1799). Patavii: II Mesaggero di S. Antonio.

Segovia Salas, R. y Sourdis Nájera, A. 2005. «Cartagena de Indias: polo imperial en el siglo XVIII», en H. Calvo Stevenson y A. Meisel Roca (eds.), Cartagena de Indias en el siglo XVIII: 260-317. Cartagena de Indias: Banco de la República.

Serrano García, M. 2015. El obispado de Cartagena de Indias en el siglo XVIII (Iglesia y poder en la Cartagena colonial). Tesis doctoral dirigida por el Dr. J. B. Ruiz Rivera. Universidad de Sevilla: Dpto. de Historia de América.

Ulloa, J. de y Ulloa, A. de. 1748. Relación histórica del viaje a la América meridional: primera parte. Tomo I. Madrid. 